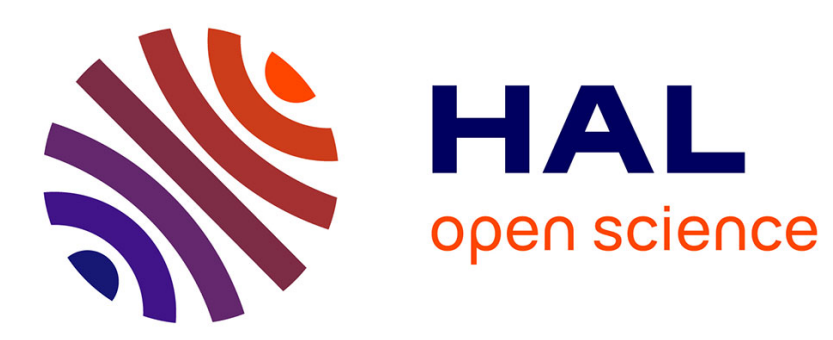

\title{
Demand and Productivity Components of Business Cycles: Estimates and Implications
}

\author{
Frédéric Dufourt
}

\section{To cite this version:}

Frédéric Dufourt. Demand and Productivity Components of Business Cycles: Estimates and Implications. Journal of Monetary Economics, 2006, 52 (6), pp.1089-1105. 10.1016/j.jmoneco.2005.08.011. hal-00279149v2

\section{HAL Id: hal-00279149 \\ https://hal.science/hal-00279149v2}

Submitted on 11 Apr 2023

HAL is a multi-disciplinary open access archive for the deposit and dissemination of scientific research documents, whether they are published or not. The documents may come from teaching and research institutions in France or abroad, or from public or private research centers.
L'archive ouverte pluridisciplinaire HAL, est destinée au dépôt et à la diffusion de documents scientifiques de niveau recherche, publiés ou non, émanant des établissements d'enseignement et de recherche français ou étrangers, des laboratoires publics ou privés. 


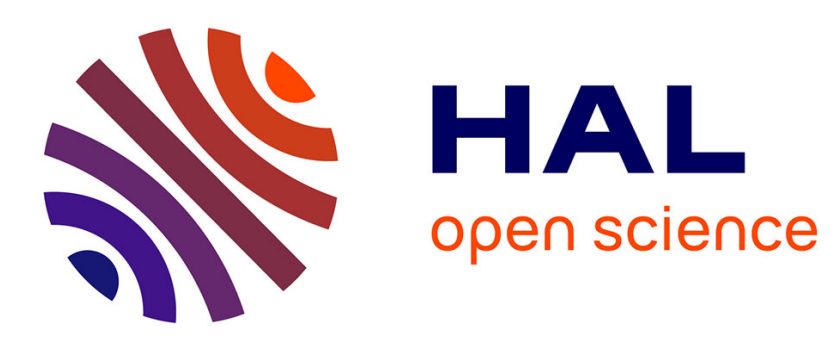

\section{Demand and Productivity Components of Business Cycles: Estimates and Implications}

Frédéric Dufourt

\section{To cite this version:}

Frédéric Dufourt. Demand and Productivity Components of Business Cycles: Estimates and Implications. 2005. halshs-00789009

\section{HAL Id: halshs-00789009 \\ https://shs.hal.science/halshs-00789009}

Preprint submitted on 15 Feb 2013

HAL is a multi-disciplinary open access archive for the deposit and dissemination of scientific research documents, whether they are published or not. The documents may come from teaching and research institutions in France or abroad, or from public or private research centers.
L'archive ouverte pluridisciplinaire HAL, est destinée au dépôt et à la diffusion de documents scientifiques de niveau recherche, publiés ou non, émanant des établissements d'enseignement et de recherche français ou étrangers, des laboratoires publics ou privés. 


\title{
Demand and productivity components of business cycles: estimates and implications
}

\author{
Frédéric Dufourt ${ }^{a * \ddagger}$ \\ ${ }^{a}$ BETA-Theme, University Louis Pasteur - Strasbourg I \\ Forthcoming in the Journal of Monetary Economics
}

\begin{abstract}
Standard stochastic growth models provide theoretical restrictions on output decomposition which can be used to investigate whether productivity shocks played a major role in observed business cycles. Applying these restrictions to US data leads to the following findings: i) Business cycles implied by productivity shocks are mildly correlated to overall fluctuations and help account for a few episodes of US postwar recessions. However, only $20 \%$ of US fluctuations can be explained by these shocks. ii) Most fluctuations seem instead to be due to "nominal demand" shocks, i.e. shocks which move output and prices in the same direction, but whose effects on output are ultimately transitory. iii) Canonical sticky price models in the New-Neoclassical Synthesis tradition can account for the cyclical comovements of output and prices, but canonical, frictionless, RBC models cannot.
\end{abstract}

Keywords: Business cycles, demand shocks, productivity shocks.

JEL codes: E32, C32, C52

\footnotetext{
* Matlab codes implementing the empirical procedure described in this paper are available at http://cournot2.u-strasbg.fr/users/beta/pagesperso/affinfos.php?id=61

${ }^{\dagger}$ BETA, UMR 7522 of CNRS. University Louis Pasteur - Strasbourg I, 61 Avenue de la Forêt Noire, F-67085 Strasbourg Cedex, FRANCE. Tel: 33-390242105, Fax: 33-390242171, E-mail: dufourt@cournot.u-strasbg.fr

${ }^{\ddagger}$ I would like to thank the editor Robert King, an anonymous referee, Antoine d'Autume, Pierre-Yves Hénin, Gilles Le Garrec, James Moss and Rodolphe Dos Santos Ferreira for very helpful comments and suggestions.
} 


\section{Introduction}

Since the influential paper by Nelson and Plosser (1982), it is widely acknowledged that many macroeconomic variables like output contain a stochastic trend. One major strength of the Real Business Cycle paradigm, initiated by Kydland and Prescott (1982), is that it provides a straightforward and convincing explanation of such a finding. In this theory, the stochastic trend in output is the result of continuous shocks affecting the level of total factor productivity, as measured by the Solow residual. Given the most obvious source of such variations in the productivity level - technological innovations - these shocks are very likely to have a permanent effect on the Solow residual and, therefore, on the long-run level of output. And there exists indeed an overwhelming piece of evidence showing that both simple and corrected measures of the US Solow residual are best described as integrated processes, being in fact very close to simple random walks (see, e.g., Prescott (1986), Burnside and Eichenbaum (1996) and Basu et al., 2004).

But the fact that part of the unconditional variability of output results from shifts in its underlying trend raises some important technical and conceptual issues. On the one hand, it imposes a sharp reconsideration of the problem of decomposition of output between meaningful trend and cyclical components, with implications for the analysis of business cycles that are of considerable importance, as we will discuss below. On the other hand, it requires a more appropriate assessment of the role of productivity shocks in business cycle fluctuations, since the fact that permanent shocks to the Solow residual contribute to the variance of output does not necessarily imply that these shocks will dominate in the business cycle, as emphasized strongly by Rotemberg and Woodford (1994, 1996). And, precisely, a major and fundamental questioning of the RBC paradigm has recently appeared in the literature, tending to deny any role of technology shocks in accounting for actual fluctuations. In particular, in a striking and assertive paper, Galí (1999) investigates the high-frequency implications of permanent productivity changes on output and concludes that these shocks have not generated "recognizable" business cycles.

The aim of this paper is to provide a consistent framework to address all these issues. In particular, we propose an approach of output decomposition which is directly inspired by, and is even based on, standard stochastic growth models in the Real Business Cycle tradition. Variations in output are interpreted as resulting typically from three main components: exogenous shocks to the productivity level (as measured by the Solow residual), cyclical movements due to the slow adjustment process of the economy in response to these productivity shocks, and cyclical movements due to other shocks that have only transitory effects on output, which we interpret - cautiously at this stage - as shocks to the various components of aggregate demand. Under the assumption that the Solow residual is a logarithmic random walk, we show that the structural representation implied by a large class of RBC models in the literature provides enough restrictions to identify these three fundamental components of output, using a simple bivariate analysis including output and another station- 
ary variable. These restrictions can therefore serve as a basis for a model-based approach to output decomposition - an approach which, we argue, is particularly desirable, especially if one wishes to evaluate the empirical relevance of these models, and to test their inherent conflicting assertion that productivity shocks have played a major role in actual fluctuations.

We apply our procedure to the US economy, and use it to study the cyclical comovements of output and prices in the face of both permanent and transitory innovations. We advocate the use of the price level as second variable, because we argue that it allows a clear assessment of the nature, monetary or not, of the structural transitory disturbance. We then use our estimates to address the following three kinds of questions:

- How important are productivity shocks in actual fluctuations?

- What is behind a typical transitory disturbance? Are monetary shocks an important component of these disturbances?

- Are standard stochastic growth models in the RBC tradition able to correctly describe the cyclical comovements of output and prices?

Our main findings can be summarized as follows. First, in sharp contrast to some recent papers in the literature, we find that productivity shocks are a non-negligible, recognizable, source of US fluctuations. They are even the leading cause of a few episodes of US postwar recessions. However, productivity shocks are clearly not the major source of this business cycle. Most fluctuations - around $80 \%$ in our estimates - seem instead to be due to shocks that have only short-run effects on output. For these shocks, the estimated comovements of output and prices strongly favor an interpretation in terms of nominal demand disturbances, in which changes in monetary conditions are likely to be of significant importance. Finally, we find that standard, flexible price models in the RBC tradition cannot account for these estimated conditional comovements, in response to either monetary or productivity disturbances. By contrast, standard sticky-price models in the New-Neoclassical Synthesis tradition come much closer to these observations.

The rest of this paper details and documents these conclusions. Section 2 provides the model-based identification scheme used for output decomposition. Section 3 provides the empirical results and discusses their implications. Section 4 evaluates the performance of some basic models in explaining the conditional cyclical components, and section 5 sets out the conclusion.

\section{A model-based approach to output decompo- sition}

This section establishes and discusses our identification procedure. As mentioned in the introduction, this identification scheme is based on the three main 
assumptions that are common to many models in the Real Business Cycle literature. These assumptions can be formally stated as follows:

i) there exist two types of structural disturbances which affect the economy, these disturbances being i.i.d. and mutually uncorrelated at all leads and lags,

ii) only one disturbance affects the trend component of output. Thus, only one disturbance has a permanent effect on the level of output,

iii) the trend component of output (the Solow residual) is a random walk.

The following proposition establishes that under these assumptions, the structural representation implied by standard stochastic growth models is sufficient to identify both the productivity trend and the cyclical components implied by each one of the two kinds of disturbances considered.

Proposition 1 Assume output $Y_{t}$ has the following structural representation

$$
\begin{aligned}
Y_{t} & =T_{t}+C_{t} \\
T_{t} & =\delta+T_{t-1}+\sigma_{z} \epsilon_{z, t} \\
C_{t} & =\Phi(L) \epsilon_{z, t}+\Psi(L) \epsilon_{x, t}
\end{aligned}
$$

with $\epsilon_{t}=\left[\epsilon_{z, t} \epsilon_{x, t}\right]^{\prime}$ and $E\left(\epsilon_{t} \cdot \epsilon_{t}^{\prime}\right)=I$.

Let $X_{t}$ be a vector composed of output (in first-difference) and any other stationary variable $x_{t}, X_{t}=\left[\Delta Y_{t} x_{t}\right]^{\prime} . X_{t}$ has a structural moving-average representation of the form $X_{t}=\gamma+A(L) \epsilon_{t}$, with $A_{0} \neq I$ and $A(1)$ has first row $\left[\begin{array}{ll}\sigma_{z} & 0\end{array}\right]$. It has a corresponding Wold representation of the form $X_{t}=\gamma+B(L) e_{t}$, with $B_{0}=I$ and $E\left(e_{t} \cdot e_{t}^{\prime}\right)=\Omega$.

Given representation $(S R)$, there is a unique non-singular matrix $S$ such that $S S^{\prime}=\Omega$ and $B(1) S$ is lower triangular. In addition, $B(1) S$ has as first row $\left[\sigma_{z} 0\right]$.

Proposition 1 implies that the knowledge of $\Omega$ and $B(1)$ are sufficient to determine $S$ and $\sigma_{z}$, and then to identify the polynomial matrix $A(L)$ and the structural disturbances $\epsilon_{t}=S^{-1} e_{t}$. It then allows the identification of $T_{t}$, $\Phi(L) \epsilon_{z, t}$ and $\Psi(L) \epsilon_{x, t}$ by setting $T_{t}=(1-L)^{-1}\left(\delta+\sigma_{z} \epsilon_{z, t}\right)$ and $\left[\Phi(L) \epsilon_{z, t} \Psi(L) \epsilon_{x, t}\right]=$ $(1-L)^{-1}[a(L)-a(1)] \epsilon_{t}$, where $a(L)=\left[a_{11}(L) a_{21}(L)\right]$ is the first row of $A(L)$.

Understanding why the assumptions implicit in representation $(S R)$ are sufficient to uncover from the data the three fundamental components of output is straightforward. Intuitively, the fact that the variance-covariance matrix of the structural disturbances is diagonal (unity), while the long-run covariance matrix of the two endogenous variables is lower triangular are sufficient conditions to identify the structural disturbances and their effect on output, as demonstrated by Blanchard and Quah (1989). In short, these assumptions allow the identification of the two components $T_{t}+\Phi(L) \epsilon_{z, t}$ and $\Psi(L) \epsilon_{x, t}$. They are not sufficient, however, to disentangle variations from the trend and variations around the 
trend in the case of a permanent disturbance. The specification of the trend is the third assumption which allows this decomposition: the trend component is simply the height at frequency 0 of the permanent component (or, equivalently, the Beveridge and Nelson (1981) trend component of $\left.T_{t}+\Phi(L) \epsilon_{z, t}\right)$, while the cyclical component is the discrepancy from this trend. This further identifies the scale factor (or variance) of the permanent innovation, $\sigma_{z}$.

\subsection{Discussion}

As we briefly mentioned, the representation (SR) is directly inspired from the structure of economic fluctuations which is implicit in most stochastic growth models in the RBC tradition. ${ }^{1}$ In these models, real output can be decomposed into a productivity trend component $T_{t}$, given by the Solow residual, and a cyclical component $C_{t}$, whose specific properties depend on the specification of the model. The Solow residual is the natural trend of output in these models, since it captures the evolution of productivity conditions over time. It determines therefore the potential level of output, i.e. the level that output would reach if the entire slow integration process of these new technology conditions had been fully realized. Arguably, these evolutions of the Solow residual occur for reasons which are not to be explained by a theory of business cycles, and are therefore mainly taken as exogenous from a business cycle perspective. ${ }^{2}$ By contrast, the cyclical component $C_{t}$ can be given a very traditional interpretation, since it describes the discrepancy between current output and its potential level, for given technology conditions. As emphasized by Rotemberg and Woodford (1996), it is therefore this component which constitutes the essence of what a business cycle theory should be able to account for. Proposition 1 follows this position explicitly, by taking full advantage of representation (SR) to characterize and focus on the empirical properties of $C_{t}$.

The identification scheme allowed by (SR) can also be considered with respect to the vast literature on decomposition of output between trend and cyclical components, when part of the unconditional variations of this series result from permanent shifts in the underlying trend. ${ }^{3}$ The issue is a particularly complex one, since a result in Quah (1992) demonstrates that there exists $a$ priori an infinite number of such decompositions, with a resulting trend which can be made arbitrarily smooth. Hence, either the degree of smoothness of the trend is chosen rather arbitrarily (as is reflected for example by the choice of the parameter $\lambda$ in the widely used Hodrick-Prescott filter), or further assumptions inspired by the theory are required to define meaningful trend and cyclical components in these series. Again, proposition 1 follows the latter conception

\footnotetext{
${ }^{1}$ Indeed, (SR) is a straightforward accommodation of the formal representation presented in King et al. (1988), extended to incorporate transitory disturbances.

${ }^{2}$ Changes in available technology conditions may originate from phenomena such as, e.g., increased R\&D spending, higher level of education, new infrastructure buildings etc... - phenomena which are more likely to be accounted for by a theory of economic growth rather than by a pure theory of economic fluctuations.

${ }^{3}$ See in particular Beveridge and Nelson (1981), Harvey (1985), Watson (1986), and Clark (1987), and the survey by Watson (1988) for other references.
} 
explicitly, by providing a model-based approach to output decomposition which uses the restrictions implied by standard stochastic growth theory.

Finally, proposition 1 allows a more formal and consistent reconsideration of the role played by productivity disturbances in observed business cycles. This topic has always remained the subject of strong debate and controversy in the empirical literature, with results reported there that are typically very contrasted (see notably Shapiro and Watson (1988), Blanchard and Quah (1989) and King et al. (1991) for prominent references). But this issue has been considerably revivified by the more recent and potentially devastating paper by Galí (1999). In particular, in parallel to the present study, several other works have also reconsidered this issue, either to comfort or to contradict Galí's main conclusions (see e.g. Francis and Ramey (2003), Basu et al. (2004), Christiano et al. (2004), and the survey by Galí and Rabanal (2004) for related references). While most of the discussion in these papers concerns Galís original finding of a negative response of hours worked to a positive technological shock, it is generally concluded that, since hours worked and output are strongly positively correlated in the data, technological shocks cannot be the main source of observed fluctuations. In that respect, one main advantage of the identification scheme proposed in proposition 1 is that it can be viewed as a new, more direct, test along this dimension, in a framework which is fully consistent with the structure of economic fluctuations implicit in standard RBC models.

\subsection{Estimation}

To apply the above procedure, we need to include in the VAR a second explanatory variable. A priori, any variable which helps to predict future output growth is a legitimate candidate for inclusion in the VAR. For example, several studies have shown that the savings ratio or the unemployment rate are good forecasters of future output growth (e.g., Blanchard and Quah (1989), Rotemberg and Woodford, 1996). However, we believe that it is even more interesting to consider the price level (in first-difference) as the second variable, and this for the following reasons. First, Table 1 shows that the inflation rate has a significant power in predicting future movements in output, since we can reject the null hypothesis of no predictive power at the $5 \%$ level (and, conversely, output growth significantly helps to predict future inflation). Secondly, and perhaps more importantly, the use of the inflation rate will allow us to make a more formal assessment of the nature of the estimated permanent and transitory disturbances. In particular, as emphasized early by Blanchard (1989), standard textbook models relying on two synthetic curves to represent some Aggregate Demand and Aggregate Supply (AD-AS) building blocks typically imply that output and prices should move, at least in the short-run, in the same direction in response to a demand shock, and in opposite direction in response to a productivity shock. Testing this simple implication is already interesting per se to qualify our interpretation of the structural disturbances. But we argue that the long-run response of prices is even more worthy of study. This is because, based on standard models of stochastic growth, we should not a priori expect that 
transitory shocks should have a strong influence on the long-run level of prices if they are not led, at least partly, by changes in monetary conditions (we discuss this point in more details below in the framework of a typical RBC model). The finding of a small or a large long-run effect on prices would therefore act as an indication of whether money or nominal variables are an influential factor in a typical estimated transitory disturbance.

\section{Empirical Results}

In accordance with the discussion above, we thus applied a VAR including output growth and inflation and 6 lags of each variable. Our data series come from the Federal Reserve Economic Database provided by the Federal Reserve Bank of St. Louis, and cover the period 1947:1-2001.1. Output is defined as the US Gross Domestic Product (expressed in billions of chained 2000 dollars, mnemonic: GDPC1), and the price level series is the Consumer Price Index (mnemonic: CPIAUCSL). ${ }^{4}$ Both series are logged and expressed in first difference.

\subsection{Demand versus productivity shocks in the US busi- ness cycle}

Fig. 1 displays the estimated cyclical component of output $-C_{t}$ - along with the fluctuations series generated by the productivity and demand disturbances, respectively. One striking feature emerging from Fig. 1(a) is that there exists a clear correspondence between the overall series $C_{t}$ and the one conditional on productivity shocks, even if the match is far from perfect (summary statistics provided in Table 2 reveal that the correlation between these two series is 0.43 ). In that respect, our results are much more favorable to the RBC paradigm than those from other empirical papers critical of this view. For example, Galí (1999) provides an estimate of the technology-induced cyclical component of output based on a bivariate regression including hours worked and labor productivity, and argues that technological shocks have hardly generated any recognizable business cycles. $^{5}$

\footnotetext{
${ }^{4}$ We use the CPI instead of the GDP deflator since the former series has slightly more predictive power of future variations in output in our bivariate representation. Results were basically unaltered, however, when we used the GDP deflator instead.

${ }^{5}$ It should be stressed, however, that our measure of productivity differs somewhat to that of Galí (1999), as it includes all kinds of shocks that have a permanent effect on output. In that respect, productivity changes can, in our estimations, be roughly interpreted as those shocks that have a permanent effect on firms' production cost schedules: this includes of course (and presumably predominantly) technological shocks, but also permanent shocks affecting the cost of inputs, like permanent variations in the price of materials or in the rates of taxation of labor and capital. By contrast, Galí (1999) defines productivity shocks as those having a permanent effect on labor productivity, and interprets them as technology shocks. In this context, permanent changes in labor taxes, for example, would be interpreted as demand shocks.
} 
Yet, if Fig. 1 supports the view that productivity shocks are an important factor of the US business cycle, it does not support the view that they are the major source of this business cycle. As shown in Fig. 1(b), most fluctuations seem instead to be due to shocks which do not affect output in the long run (the correlation between the two series is 0.89). As long as our interpretation that these transitory shocks mainly reflect variations in aggregate demand is correct (an assumption that we will assess later), it is therefore demand shocks that clearly appear to be the major source of US postwar business cycles.

Table 2 provides other statistics illustrating these main observations. In particular, observe that, since the two structural disturbances $\epsilon_{z, t}$ and $\epsilon_{x, t}$ are by construction uncorrelated, the variance of the cyclical component $C_{t}$ is asymptotically given by the sum of the squared terms in the estimated polynomials $\Phi(L)$ and $\Psi(L)$. It is then straightforward to compute an estimate of the contribution of demand and productivity shocks to the overall business cycle, by comparing how much of the variance of $C_{t}$ is accounted for by the conditional series $\Phi(L) \epsilon_{z, t}$ and $\Psi(L) \epsilon_{x, t}$. It appears from our estimations that only $20 \%$ of US output fluctuations are accounted for by productivity disturbances, the remaining $80 \%$ being due to our estimated transitory disturbance. This confirms that productivity shocks are not the main factor responsible for these fluctuations.

\subsection{Estimated fluctuations and US postwar recessions}

Most results emphasized in the previous paragraph are derived from a particular identification procedure. While we have argued that this procedure follows directly from the structure implicit in current stochastic growth models, it is important to check its ability to identify "realistic" business cycles. To do so, we have followed the usual practice of verifying whether the estimated business cycle series extracted from our procedure are able to correctly identify the main periods of recessions in the US postwar economic history, as they were dated and identified by the National Bureau of Economic Research (NBER).

Fig. 2 reports our estimated conditional cyclical components along with the troughs of recessions as determined by the NBER (vertical lines). Note that, in order to make negative values of the business cycle coincide with absolute declines in output, we have in fact represented minus the corresponding series in the case of the productivity-induced cyclical component (Fig. 2a). ${ }^{6}$

Results from this experiment are instructive. They first reinforce our measures of the business cycle, since all periods of US recessions are clearly associated with negative values of at least one of the two conditional cyclical components. Furthermore, the 1949, 1954, 1961, 1982 and 1991 recessions seem to have been mostly generated by contractions in aggregate demand, while the

\footnotetext{
${ }^{6}$ As emphasized by Rotemberg and Woodford (1996), positive productivity shocks in a standard Real Business Cycle model induce an increase in output which is gradual and smaller in absolute value than the increase in the Solow residual. Output being below trend during this transition process, its cyclical component is negative in response to a positive productivity shock.
} 
1974 and 1980 recessions seem to be mainly the results of negative productivity shocks. The 1958 and 1970 recessions appear as a combination of both supply and demand contractions. Although we do not provide here a detailed analysis of these critical periods in the US business cycle, we view this overall picture of US postwar recessions as being roughly consistent with the less formal descriptions of these episodes in several analyses of the American business cycle. ${ }^{7}$

\subsection{Impulse response analysis}

The empirical impulse response functions to each kind of disturbance contain a lot of information which can be used to draw some inference on the nature of the shocks which are under way in the economy. Consider for example a reference economy in which the simplest version of the quantitative theory of money holds, i.e. an economy in which we have at the aggregate level: $Y_{t}=M_{t} / P_{t}$. In this economy, any long-run decrease in the price level must be generated by either a shock which permanently increases output (a positive productivity shock), or by a change in the aggregate quantity of money $M_{t}$ (say, a monetary shock). Transitory shocks which are not accompanied by changes in monetary conditions should only modify prices in the short-run.

Hence, a simple way to draw some inference on the nature of the structural disturbances is to consider whether a long-run increase in output is associated with a long-run decrease in prices (in the case of a productivity disturbance), and whether a short-run increase in output is associated with a long-run increase in prices in the case of a temporary disturbance. In particular, in the latter case, any finding of such variations in long-run prices would act as an indication that changes in monetary conditions may probably be an important part of a typical transitory disturbance. ${ }^{8}$

Fig. 3(a,b) shows precisely that following a one standard deviation permanent innovation, output gradually increases towards its new long-run level (so that its cyclical component is negative), while prices gradually decline in broadly similar proportions. ${ }^{9}$ The initial expansion of output after the shock

\footnotetext{
${ }^{7}$ Of course, we did not specifically capture in our analysis the particular role played by the 1973 and 1979 oil crises. Note however that, as mentioned earlier, our implicit definition of productivity is large enough to accommodate such episodes, as a permanent increase in the price of materials can be interpreted as a permanent shift in the production costs schedule, and thus looks very much like productivity regress.

${ }^{8}$ Our interpretation of the transitory disturbance does not exclude the possibility that the initial shock which has led to a change in output may not be monetary, and that the observed increase in prices simply reflects the endogenous response of monetary authorities to this otherwise real phenomenon. While there is nothing to contradict this view, it remains true that monetary factors have also been active during this transition process. Isolating the part of the response of output which is due to the original shock and the part which is implied by the endogenous response of the monetary authorities is a very difficult task which is beyond the scope of this paper. See Bernanke et al. (1997) for a contribution in this line.

${ }^{9}$ Contrarily to the case of real variables such as output, there is not an obvious definition of the trend for the price level. In order to facilitate comparisons, we simply define the cyclical component of prices as the forecastable component of this series. As demonstrated by Beveridge and Nelson (1981), this implies that the trend component of prices also follows a random walk, although we do not interpret it as the 'natural' trend for this variable.
} 
is only moderate - it accounts for about $50 \%$ of the total future expansion but it is somewhat larger than what is found in other recent studies (e.g. Basu et al., 2004). As discussed in King et al. (1988), such a gradual expansion in output after technological shocks can be usefully described by the mechanisms emphasized in the Real Business Cycle literature. However, as we will emphasize later, standard frictionless RBC models predict an adjustment of output which is much faster in the model than the one which is observed in Fig. 3.

Fig. 3(c,d) plots the results for the estimated transitory disturbance. Following a positive one standard deviation shock, output strongly increases during the first few periods following the shock, and then slowly returns to its initial level. The rise in output peaks 3 quarters after the shock, and real effects are significant for about 10 quarters. Once again, this typical hump-shaped response of output to a transitory/demand shock was found in numerous empirical studies and has been revealed to be a robust feature across specifications and identification schemes. Our empirical impulse response functions are thus in accordance with this widely documented empirical regularity.

But the most striking result in Fig. 3(c,d) concerns the predicted behavior of prices. This figure shows that, while output starts to return to its initial level three quarters after the shock, the price level continues rising in huge proportions during all the transition process. In the end, the overall increase in prices is around 2 percent. Hence, a typical transitory shock ends up by a large increase in output expressed in nominal terms (or, equivalently, in the nominal level of aggregate demand), while real output is unaffected in the long-run. As we stressed above, we interpret such a striking finding as an indication that nominal factors and changes in monetary conditions are probably an important part of a typical transitory disturbance.

\section{Stochastic growth models and the comovements of output and prices}

A related important issue which can be addressed using the methodology emphasized above is to assess whether current stochastic growth models in the RBC tradition are able to correctly describe the three fundamental components of output $T_{t}, \Phi(L) \epsilon_{z, t}$ and $\Psi(L) \epsilon_{x, t}$. This is an important methodological question since, from a theoretical point of view, any model of the business cycle verifying representation $(S R)$ can be viewed as a set of restrictions on the polynomials $\Phi(L)$ and $\Psi(L)$, for a given evolution of the Solow residual. Hence, if a model is correctly specified, it should generate business cycle properties for $C_{t}$ which are broadly consistent with those inferred from our empirical procedure. A simple test of success for existing competing models is thus to verify the degree to which they are consistent with these empirical conditional cyclical components.

While this general methodology could easily be applied to any model of the business cycle satisfying $(S R)$, we will only consider here the predictions of two 
of the most popular and competing models: a simple RBC model with flexible prices, and a simple sticky-prices model in the New-Neoclassical Synthesis tradition, following the terminology proposed by Goodfriend and King (1997).

\subsection{The Model}

We describe very briefly the general model that we wish to consider, since it is explained in more details in Dufourt (2004), and since it is a very canonical version of current business cycle models proposed in the literature, in which both technological and monetary shocks affect the economy, in a framework where firms face possibly some adjustment costs for modifying their prices. When the adjustment cost is set to zero, prices are fully flexible and the model behaves very much like a standard Real Business Cycle model, with the minor difference that there is imperfect competition on the product market. When the cost is positive, on the contrary, prices are sticky and the model behaves like a typical model in the New Neoclassical Synthesis tradition. As shown in Dufourt (2004), the version of the model with sticky prices is able to account for the unconditional cyclical components of many macroeconomic variables. However, since the present analysis is bivariate and includes only output and the price level, we will restrict our attention to the business cycle properties of these two variables.

From now on, let us denote by $C$ consumption, $H$ hours worked, $Y$ production, $K$ capital, $I$ investment, $M$ money holdings, $P$ prices, $W$ wages, $S$ bank deposits, $R$ nominal interest factor, $\Pi$ firms profits, and $F$ banks profits.

Households: There is a representative household which maximizes its intertemporal utility function $E_{0} \sum_{t=0}^{\infty} \beta^{t}\left\{\ln C_{t}-A H_{t}\right\}$ subject to the following constraints for each date $t: M_{t-1} \geqslant S_{t}+P_{t} C_{t}$, and $M_{t} \leqslant W_{t} H_{t}+S_{t} R_{t}+\Pi_{t}+$ $F_{t}+\left(M_{t-1}-S_{t}-P_{t} C_{t}\right)$. The first constraint is a cash-in-advance restriction stating that the household must allocate its amount of money accumulated from the preceding period to bank deposits and cash required to buy the consumption good. ${ }^{10}$ The second constraint is the intertemporal budget constraint requiring that the amount of money accumulated for the next period be equal to wage earnings, interest-augmented deposits, ex-post dividends from firms and banks and the eventual unused amount of money.

Firms: The economy contains a continuum of firms which produce differentiated goods. These firms are required to finance investment purchases on a pre-paid basis by borrowing from the bank the appropriate amount of cash at the nominal interest factor $R_{t}$. Each firm $i$ thus maximizes its expected inflows of profits $E_{0} \sum_{t=0}^{\infty} \beta^{t} \frac{U_{c, t+1}}{U_{c, t}}\left\{P_{t} Y_{t}^{i}-W_{t} H_{t}^{i}-P_{t} I_{t}^{i} R_{t}-P_{t} C\left(P_{t}^{i} / P_{t-1}^{i}\right)\right\}$, subject to the constraints $Y_{t}^{i}=\left(P_{t}^{i} / P_{t}\right)^{-\theta} Y_{t}$ (demand function), $Y_{t}^{i}=\left(K_{t}^{i}\right)^{\alpha}\left(z_{t} H_{t}^{i}\right)^{1-\alpha}-$ $z_{t} \phi$ (production function), $K_{t+1}^{i}=(1-\delta) K_{t}^{i}+I_{t}^{i}$ (law of motion of capital),

\footnotetext{
${ }^{10}$ We introduce banks in this model in order to have an income-based demand of money at equilibrium: $Y_{t}=M_{t} / P_{t}$. This is to conform better with the discussion in the preceding section.
} 
and $C\left(P_{t}^{i} / P_{t-1}^{i}\right)=\frac{\Phi_{P}}{2}\left(P_{t}^{i} / P_{t-1}^{i}-\pi\right)^{2} Y_{t}$ (adjustment cost of prices), where $z_{t}$ is an exogenous labor-augmenting technological progress, $\phi$ is a fixed-cost, and $\delta \in[0,1]$ is the depreciation rate of capital. The adjustment cost function is measured in terms of the final good and is taken from Rotemberg (1982): $\Phi_{P} \geqslant 0$ is a parameter governing the size of the adjustment costs, and $\pi$ is the steady state rate of inflation.

Financial intermediaries: Financial intermediaries are supposed to act in a perfectly competitive loans market. At the beginning of period $t$, the representative financial intermediary receives deposits from the households and new cash injections $X_{t}$ from the monetary authority. It then lends its total amount of deposits to the firms at the gross interest factor $R_{t}$. At the end of the period, firms pay back their loans, and the financial intermediary remunerates households' deposits at the interest factor $R_{t}$. It then makes a profit $F_{t}=R_{t} X_{t}$, which it redistributes to the representative household via dividend payments.

Driving processes: In accordance with our empirical framework, we assume that the economy is perturbed by two kinds of disturbances. The first one affects the Solow residual, which is assumed to follow a logarithmic random walk with drift: $\ln z_{t}=\ln z_{t-1}+\mu+\epsilon_{z, t}$, where $\epsilon_{z, t}$ is a serially uncorrelated technological shock. The second disturbance is monetary. The monetary authority is assumed to manage the nominal money supply $M_{t}$ by injecting new cash $X_{t}$ via lumpsum transfers to the financial intermediaries, i.e. $M_{t}=M_{t-1}+X_{t}$. As in Galí (1999), we assume that the monetary authority follows a simple policy rule: $\ln x_{t}=\left(1-\rho_{x}\right) \ln \bar{x}+\rho_{x} \ln x_{t-1}+\epsilon_{x, t}$, where $x_{t}=M_{t} / M_{t-1}$ is the growth rate of money and $\epsilon_{x, t}$ is a serially-uncorrelated monetary shock.

Calibration: To evaluate the model and compute the theoretical impulse response functions, we have used the following calibration: $\beta=0.99, \alpha=0.3$, $\delta=0.025, \mu=1.004, \bar{x}=1.01, \rho_{x}=0.6$ and $\theta=6$, implying a steady state markup of 1.2. Furthermore, the preferences parameter $A$ is fixed so that households spend $20 \%$ of their time working at the steady-state, and the fixed$\operatorname{cost} \phi$ is calibrated so that firms profits are null at the steady state. Finally, in the RBC version of the model, we set $\Phi_{P}=0$ (no adjustment costs of prices), while in the NNS version, we set $\Phi_{P}=40$ (strong adjustment costs of prices).

\subsection{Simulations results}

We now present the results obtained by simulating both versions of the model when the economy is affected, respectively, by a technological shock and a monetary disturbance.

\subsubsection{Results for the RBC model}

A comparison of the cyclical components implied by the RBC model and the corresponding estimated cyclical components is provided in Fig. 4. From this figure, it is clearly apparent that the RBC model fails to account for the cyclical 
components of output and prices, the predicted impulse response functions being largely outside the $95 \%$ confidence interval computed from the data. ${ }^{11}$

In response to a $1 \%$ technological innovation, the $\mathrm{RBC}$ model predicts that output converges to its new long-run level from below, so that its cyclical component is negative. As stressed earlier, King et al. (1988) emphasize that this gradual adjustment occurs because the specification of consumers' preferences implies that there are intertemporal substitution effects which incite the agents to smooth consumption's variations over time. While the qualitative effects resulting from this mechanism do not contradict the data, the speed of this adjustment process is far greater in the model than it is in the data: In the model, practically $80 \%$ of the total increase in output takes place during the first quarter. By contrast, the data suggest that 10 quarters at least are required before output reaches this $80 \%$ level. Note that this is true even though the estimated initial expansion of output reported in the previous section is generally larger than what is found in several related papers. ${ }^{12}$ Thus, even if our empirical results are somewhat less unfavorable to the RBC model than other studies, they clearly illustrate the difficulties of this model to explain the slow adjustment process followed by output after an improvement in technology conditions.

The predicted behavior of prices after a technological innovation is also in sharp contradiction with the data. Unsurprisingly in the light of the discussion above, the price level in the model - whose evolution is closely related to that of output, due to the aggregate money-output equation - adjusts much faster to its new long-run level than the corresponding series in the data.

Finally, the failures of this canonical RBC model with flexible prices are even more apparent if we consider the predictions of this model in response to a monetary disturbance. Since, in the absence of any rigidity in prices, money acts in this framework as a simple inflation tax, any increase in the growth rate of money implies that output instantaneously declines in the short-run, before gradually returning to its initial level. Of course, due again to the money-output equation, this decline in output is also accompanied by a sharp increase in prices. Neither predictions are consistent with the estimated impulse response functions, which suggest a strong and persistent increase in output together with a slow and gradual adjustment of prices in response to a nominal demand disturbance.

\subsubsection{Results for the NNS model}

The empirical results suggest that a slower adjustment of prices could potentially help better explain the empirical cyclical components. It is therefore interesting to consider the predictions of the model when adjustment costs have to be paid by firms to modify their nominal prices. The cyclical components of output and prices implied by the NNS model after technological and monetary disturbances

\footnotetext{
${ }^{11}$ This confidence interval was calculated by bootstrap, using 500 innovations taken in the normal law.

${ }^{12}$ For example, Blanchard and Quah (1989), Galí (1999) and Basu et al. (2004) report an initial response of output to technological disturbances which is close to zero.
} 
are reported in Fig. 5.

From this figure, it appears immediately that the match with the data is far better than with the flexible prices model. In particular, if, from a qualitative point of view, the presence of a rigidity in prices does not really alter the way the economy responds to a technological innovation (after a one percent permanent increase in technology conditions, output still converges to its new long-run level from below, and prices gradually decline to their new steady state), the speed of this adjustment process is much slower than it was in the preceding model. This is because the adjustment of prices is now too slow to ensure an expansion in real balances (and, thus, in aggregate demand) sufficient to absorb the potential of supplementary production generated by the sharp increase in production possibilities. This simple mechanism seems to be consistent with the slow adjustment process of output found in the data after a technological innovation.

But the changes in the model predictions are even more important for what concerns the cyclical components of output and prices in response to a monetary disturbance. In particular, because prices no longer adjust instantaneously to modifications of the economic environment, any additional injection of money generates a real increase in aggregate demand, which is partially accommodated by firms increasing their quantities produced and sold. Thus, output gradually rises during a few periods after the shock, in a way which seems in accordance with what is suggested by the data. However, as long as prices are gradually adjusted to their new long-run optimal level, the real effects on output vanish over time. As shown in Fig. 5, all these predictions of the NNS model are in accordance with the $95 \%$ confidence interval computed from the data.

Overall, this simple dynamic general equilibrium model with sticky prices seems able to correctly account for the cyclical components of output and prices after either technological shocks or nominal disturbances.

\section{Conclusion}

A central message of the RBC paradigm is that technology shocks account not only for growth (that is, changes in productivity conditions that have a permanent effect on the level of output), but also for an important part of economic fluctuations. This view has been recently challenged on empirical grounds by Galí (1999) and others, who show that the estimated high-frequency implications of permanent productivity changes on output are poorly correlated with the periods of recession identified by the NBER.

In this paper, we have addressed a similar issue by exploiting more fully the structure of current stochastic growth models, which are at the heart of the RBC paradigm. In particular, we used a model-based identification scheme which allowed us to disentangle variations in the data which result from a shift in the underlying trend - and which, therefore, are more likely to be accounted for by a theory of economic growth - and variations around this trend, which are mainly those which should be explained by a theory of economic fluctuations. 
Our main finding is that if US fluctuations are partly explained by changes in technology conditions, productivity shocks typically explain around $20 \%$ of actual fluctuations. Most fluctuations seem instead to be due to "nominal demand" shocks, i.e. shocks which move output and prices in the same direction, but whose effects on output are ultimately transitory.

In addition, we have shown that simple frictionless models in the RBC tradition are not able to account for the empirical impulse response functions. These conditional cyclical components are by contrast well described by canonical models in the New Neoclassical Synthesis tradition, in which productivity and monetary disturbances affect an economy characterized by sticky prices. In accordance with a recent, growing literature, our empirical results therefore cast new doubts on the view that productivity shocks are the predominant source of economic fluctuations, and that purely frictionless models are prominent candidates to account for these fluctuations.

\section{References}

[1] Basu, S., Fernald, J., Kimball, M., 2004. Are technology improvements contractionary? NBER Working Paper \#10592, forthcoming in the American Economic Review.

[2] Bernanke, B., Gertler, M., Watson, M., 1997. Systematic monetary policy and the effects of oil price shocks. Brookings Papers on Economic Activity, 91-157.

[3] Beveridge, S., Nelson, C. R., 1981. A new approach to decomposition of economic time series into permanent and transitory components with particular attention to the measurement of the business cycle. Journal of Monetary Economics 7, 151-174.

[4] Blanchard, O. J., 1989. A traditional interpretation of macroeconomic fluctuations. American Economic Review 79, 1146-1164.

[5] Blanchard, O. J., Quah, D., 1989. The dynamic effects of aggregate demand and supply disturbances. American Economic Review 79, 655-673.

[6] Burnside, C., Eichenbaum, M., 1996. Factor-hoarding and the propagation of business-cycle shocks. American Economic Review 86, 1154-1174.

[7] Christiano, L. J., Eichenbaum, M., Vigfusson, R., 2004. What happens after a technology shock? Working Paper, Northwestern University.

[8] Clark, P. K., 1987. The cyclical component of U.S. economic activity. Quarterly Journal of Economics 102, 197-814.

[9] Dufourt, F., 2004. Dynamic General Equilibrium models and the Beveridge-Nelson facts. Working Paper, BETA, University Louis Pasteur, Strasbourg, downloadable at http://cournot2.ustrasbg.fr/users/beta/pagesperso/affinfos.php?id=61. 
[10] Francis, N., Ramey, V. A., 2003. Is the technology-driven real business cycle hypothesis dead? Shocks and aggregate fluctuations revisited. Working Paper, UCSD, forthcoming in the Journal of Monetary Economics.

[11] Galí, J., 1999. Technology, employment, and the business cycle: Do technology shocks explain aggregate fluctuations? American Economic Review 89, 249-271.

[12] Galí, J., Rabanal, P., 2004. Technology shocks and aggregate fluctuations: how well does the RBC model fit postwar U.S. data? Working Paper, University Pompeu Fabra.

[13] Goodfriend, M., King, R. G., 1997. The New Neoclassical Synthesis and the role of monetary policy. NBER Macroeconomics Annual 12, 231-295.

[14] Harvey, A. C., 1985. Trend and cycle in macroeconomic time series, Journal of Business and Economic Statistics 3, 216-227

[15] King, R. G., Plosser C. I., Rebelo, S. T., 1988. Production, growth and business cycle II. New directions. Journal of Monetary Economics 21, 309341.

[16] King, R. G., Plosser C. I., Stock, J. H., Watson, M. W., 1991. Stochastic trends and economic fluctuations. American Economic Review 81, 819-840.

[17] Kydland, F. E., Prescott, E., 1982. Time to build and aggregate fluctuations, Econometrica 50, 1345- 1370.

[18] Nelson, C. R., Plosser, C. I., 1982. Trends and random walks in macroeconomic time series. Journal of Monetary Economics 10, 139-162.

[19] Prescott, E. C., 1986. Theory ahead of business cycle measurement. Carnegie-Rochester Conference Series on Public Policy 25, 11-44.

[20] Quah, D., 1992. The relative importance of permanent and transitory components: identification and some theoretical bounds. Econometrica 60, 107118.

[21] Rotemberg, J. J., 1982. Sticky prices in the United States. Journal of Political Economy 90, 1187-1211.

[22] Rotemberg, J. J., Woodford, M., 1994. Is the business cycle a necessary consequence of stochastic growth?, NBER Working Paper \#4650.

[23] Rotemberg, J. J., Woodford, M., 1996. Real-business-cycle and the forecastable movements in output, hours, and consumption. American Economic Review 86, 71-89.

[24] Shapiro, M. D., Watson, M. W., 1988. Sources of business cycle fluctuations. NBER Macroeconomics Annual, 111-148. 
[25] Watson, M. W., 1986. Univariate detrending methods with stochastic trends. Journal of Monetary Economics 18, 49-75.

[26] Watson, M. W., 1988. Variable trends in economic time series. Journal of Economic Perspectives 2, 147-174. 
Table 1 - Granger Causality test for $\Delta y$ and $\Delta p$ (6 lags)

\begin{tabular}{|c|c|c|c|c|c|}
\hline \multicolumn{3}{|c|}{ endogenous: $\Delta y$} & \multicolumn{3}{|c|}{ endogenous: $\Delta p$} \\
\hline Variable & F-value & Prob & Variable & F-value & Prob \\
\hline$\Delta y$ & 4.85 & 0.0001 & $\Delta y$ & 2.90 & 0.0098 \\
\hline$\Delta p$ & 2.60 & 0.0234 & $\Delta p$ & 76.15 & 0.0000 \\
\hline
\end{tabular}




\begin{tabular}{lll}
\hline \hline Productivity: $\quad C_{z, t}=\Phi(L) \epsilon_{z, t}$ & $\operatorname{Corr}\left(C_{t}, C_{z, t}\right)=0.43$ \\
& & $\operatorname{Var}\left(C_{z, t}\right) / \operatorname{Var}\left(C_{t}\right)=0.20$ \\
& \\
Demand: & $C_{x, t}=\Psi(L) \epsilon_{x, t}$ & $\operatorname{Corr}\left(C_{t}, C_{x, t}\right)=0.89$ \\
& & $\operatorname{Var}\left(C_{x, t}\right) / \operatorname{Var}\left(C_{t}\right)=0.80$ \\
&
\end{tabular}


$\frac{\pi}{6}$

$\rightarrow$

$\frac{1}{\underline{0}}$

(

으.

$\overline{\bar{D}}$

$\frac{\delta}{\frac{D}{C}}$

อ

금

을

ఏ

으

(1)

s

尺

$\overline{\bar{\sigma}}$

(D)

$\overrightarrow{ }$

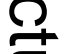

Q)

के

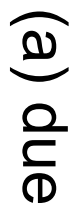

응

응

을

$\stackrel{\frac{\rho}{}}{\bar{z}}$

₹

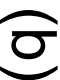

음

ㅇ

ㅇ

$\frac{\mathbb{D}}{3}$

을
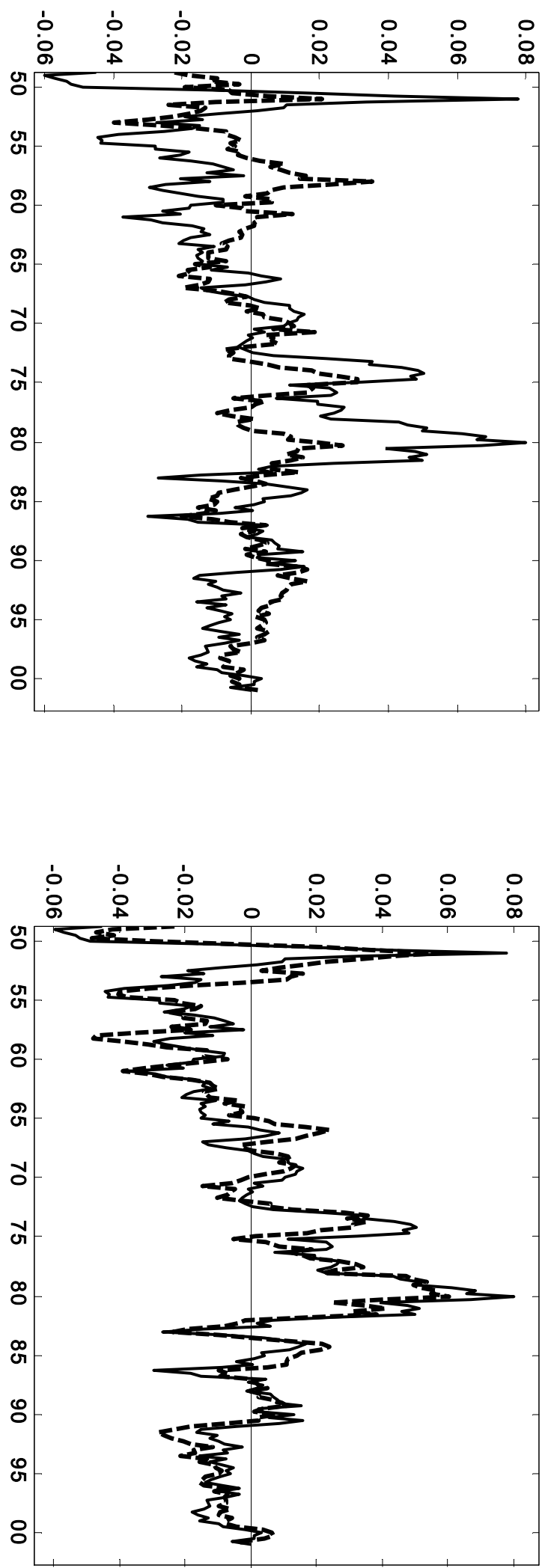
$\frac{\pi}{6}$

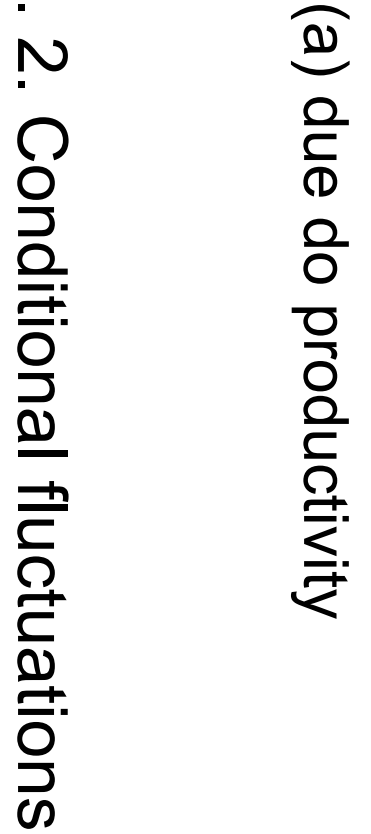

$\stackrel{0}{2}$

吕

Tा

흠

ติ

ज

오

तD

ค

क

(A)

के
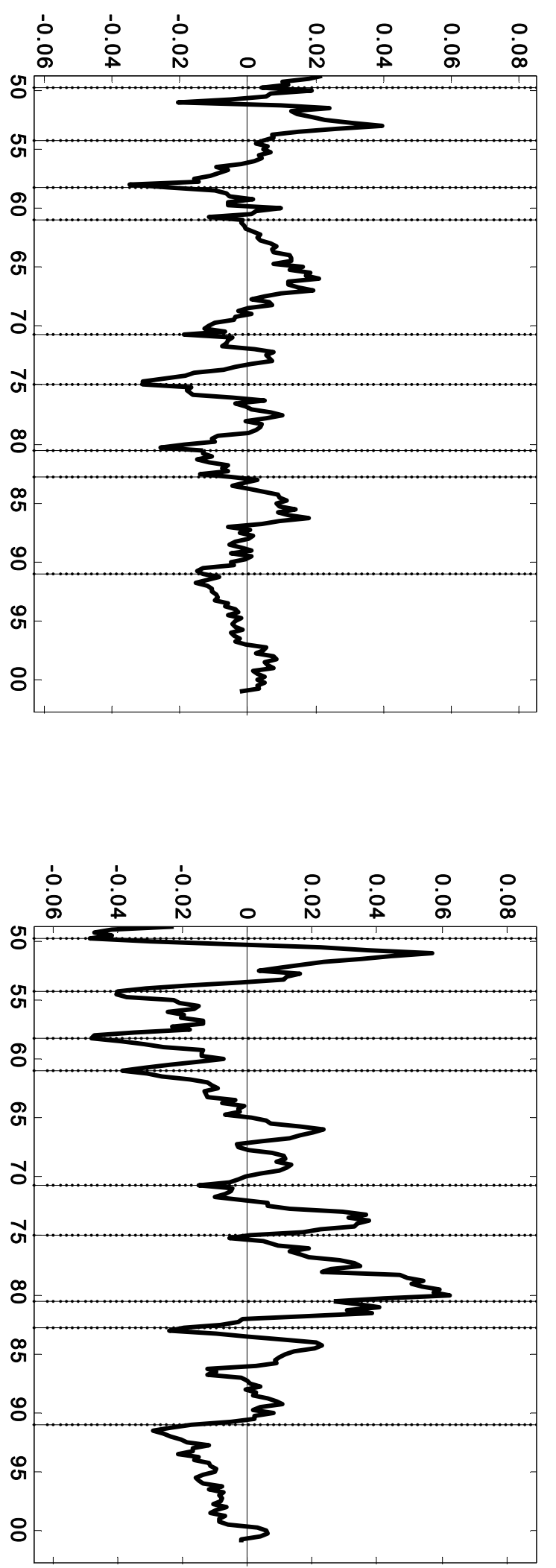


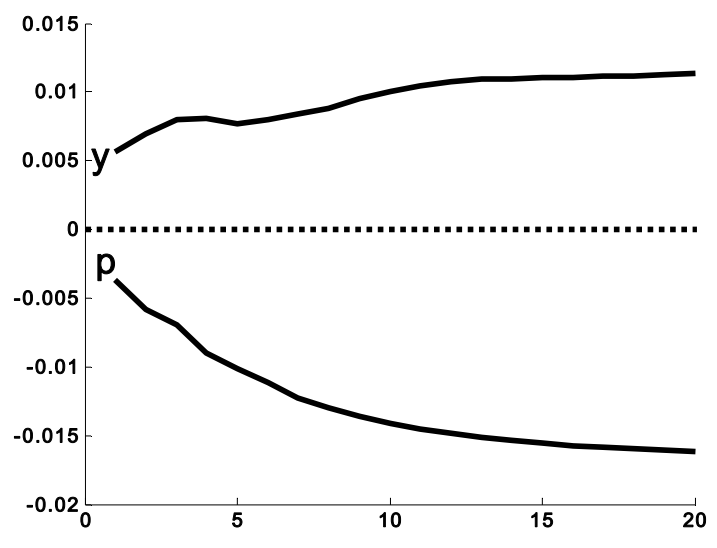

(a) IRF to supply shock

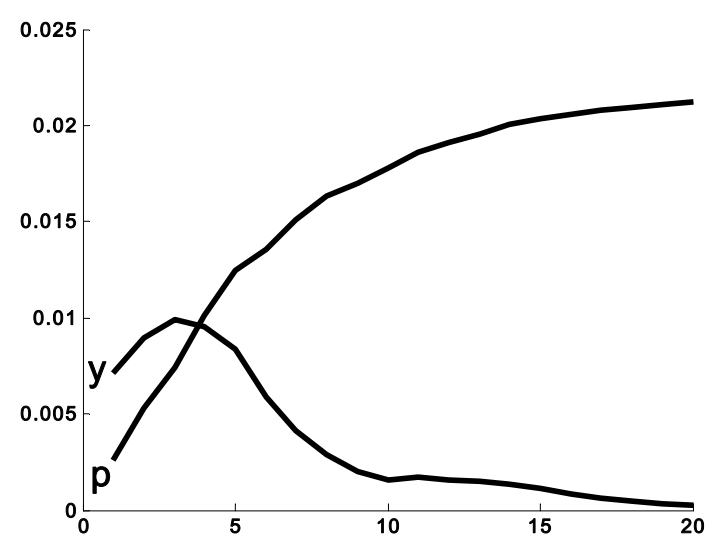

(c) IRF to demand shock

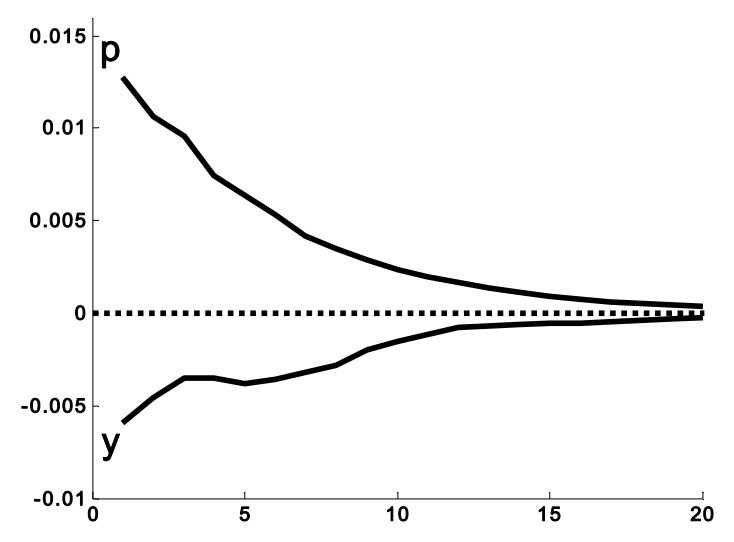

(b) Cyclical component - supply shock

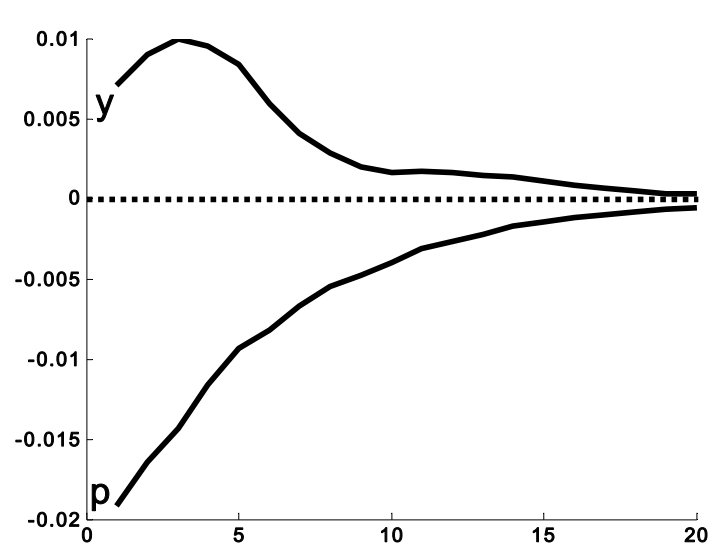

(d) Cyclical component - demand shock

Fig. 3. Impulse response functions and corresponding cyclical components. 

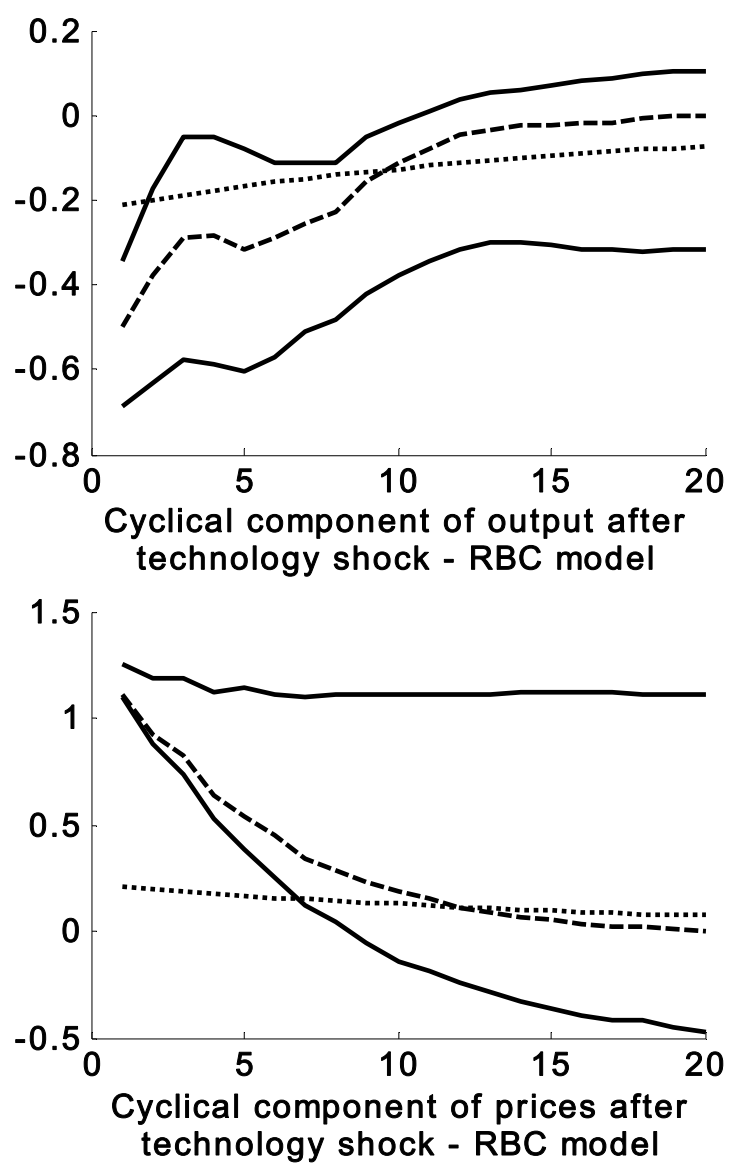
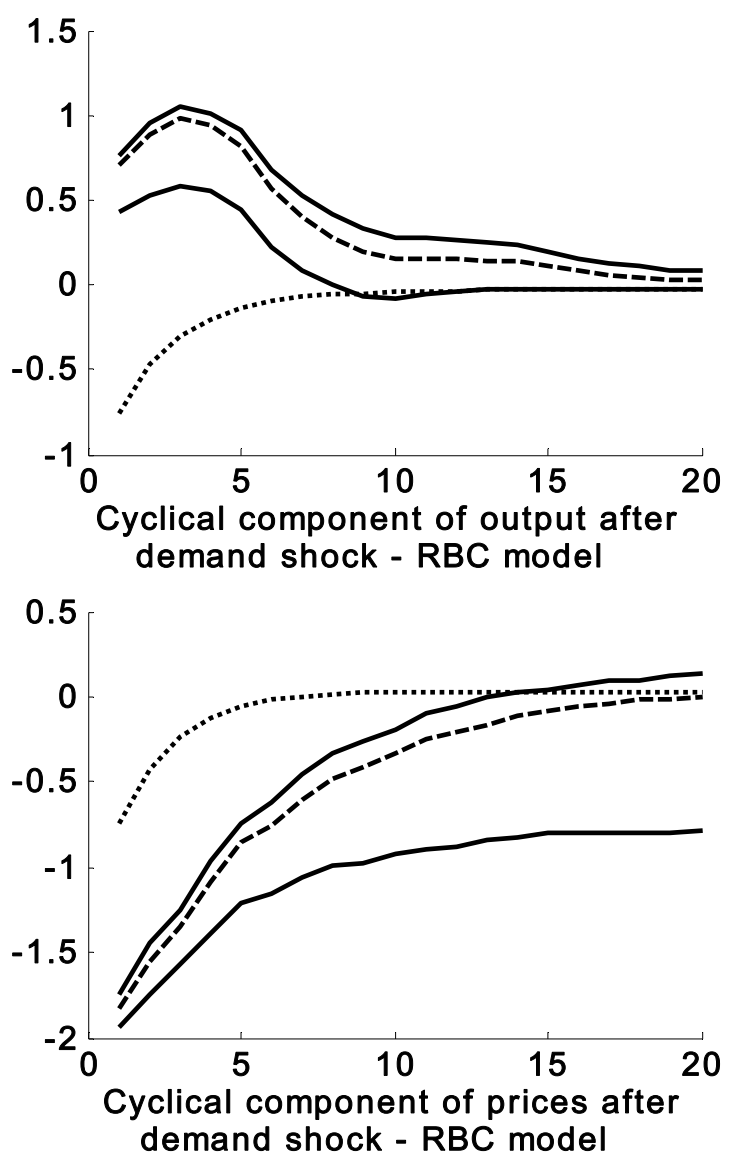

Fig. 4. Empirical (long dashed) versus predicted (short-dashed) cyclical components - RBC model. 

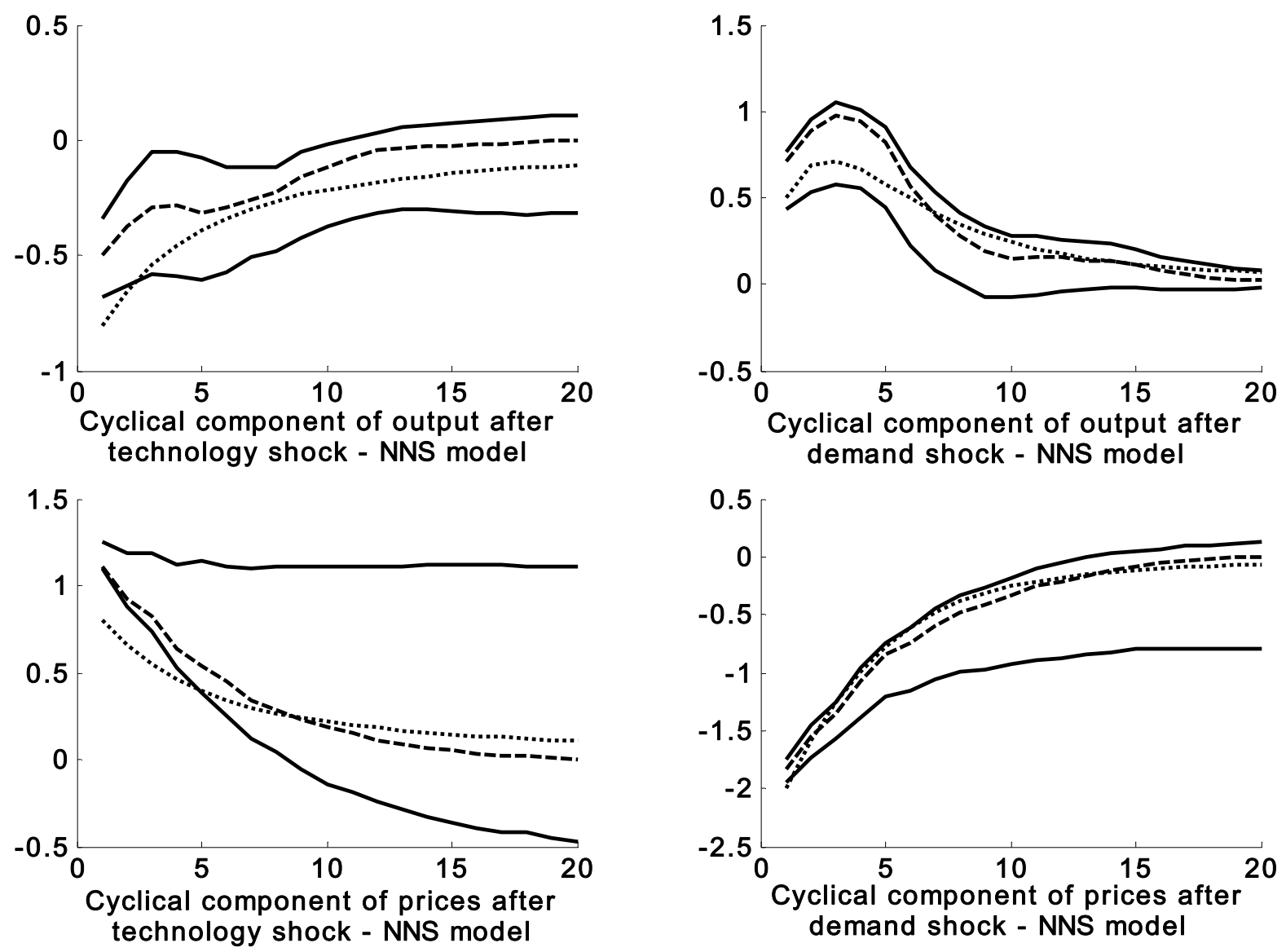

Fig. 5. Empirical (long dashed) versus predicted (short-dashed) cyclical components - NNS model. 